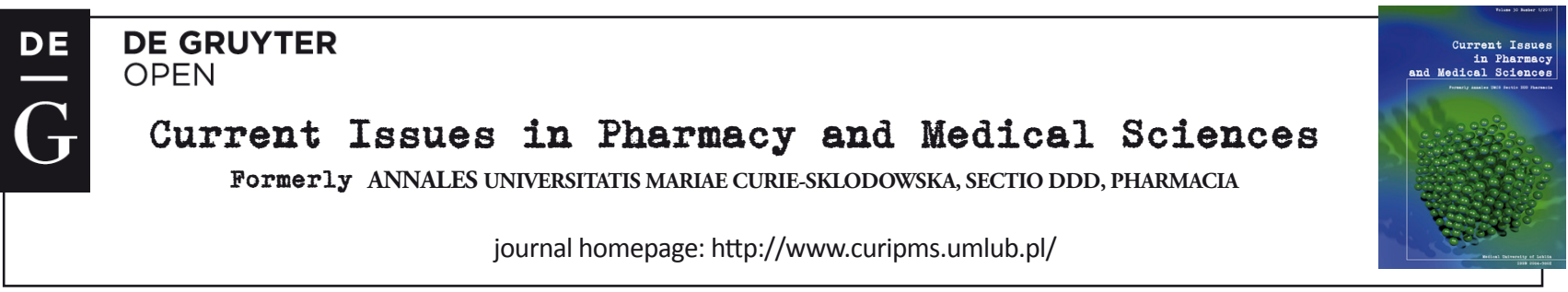

\title{
Synthesis and characterization of related substances of Azilsartan Kamedoxomil
}

\author{
N V D Harikiran Maddi ${ }^{1,2}$, Srinivas Garaga ${ }^{1,2 \star}$, Ambati V. Raghava Reddy ${ }^{1}$, \\ Paul Douglas Sanasi ${ }^{2}$, Raghubabu Korupolu ${ }^{2}$
}

\begin{abstract}
${ }^{1}$ Chemical Research and Development Department, Aurobindo Pharma Ltd, Survey No: 71\&72, Indrakaran Village, Sangareddy Mandal, Medak district, Hyderabad - 502329, Andhra Pradesh, India

${ }^{2}$ Department of Engineering Chemistry, A. U. College of Engineering (A), Andhra University, Visakhapatnam - 530 003, Andhra Pradesh, India
\end{abstract}

ARTICLE INFO
Received 12 April 2017
Accepted 25 April 2017

Keywords:

Azilsartan Kamedoxomil,

related substances,

synthesis,

characterization.

\begin{abstract}
Azilsartan Kamedoxomil is an AT1-subtype angiotensin II receptor blocker (ARB). During the laboratory synthesis of Azilsartan Kamedoxomil, four related substances of Azilsartan Kamedoxomil were observed and identified. These were 2-Ethoxy-3-[[4-[2[4-[(5-methyl-2-oxo-1,3-dioxol-4-yl)methyl]-5-oxo-1,2,4-oxadiazol-3-yl]phenyl]phenyl] methyl] benzimidazole-4-carboxylic acid (azilsartan N-medoxomil, 9), (5-methyl-2-oxo1,3-dioxol-4-yl)methyl 2-ethoxy-3-[[4-[2-[4-[(5-methyl-2-oxo-1,3-dioxol-4-yl)methyl]-5oxo-1,2,4-oxadiazol-3-yl]phenyl]phenyl] methyl] benzimidazole-4-carboxylate (azilsartan dimedoxomil, 10), (5-methyl-2-oxo-1,3-dioxo-4-yl)methyl 1-[2'-(4,5-dihydro-5-oxo-4H1,2,4-oxadiazol-3-yl)biphenyl-4-yl]methyl]-2-methoxy-1H-benzimidazole-7-carboxylate (methoxy analogue of azilsartan medoxomil, 11), Methyl 1-((2'-amidobiphenyl-4-yl) methyl)-2-ethoxy-1H-benzo[d]imidazole-7-carboxylate (amide methyl ester, 12). The present work describes the origin, synthesis and characterization of these related substances.
\end{abstract}

\section{INTRODUCTION}

Azilsartan Kamedoxomil is an $\mathrm{AT}_{1}$-subtype angiotensin II receptor blocker (ARB). Angiotensin II is formed from angiotensin I in a reaction catalyzed by angiotensin converting enzyme, and angiotensin II is the principal pressor agent of the rennin-angiotensin system $[1,12]$, with effects that include vasoconstriction, stimulation of synthesis and release of aldosterone, cardiac stimulation, and renal reabsorption of sodium. Azilsartan Kamedoxomil blocks the vasoconstrictor and aldosterone-secreting effects of angiotensin II by selectively blocking the binding of angiotensin II to the $\mathrm{AT}_{1}$ receptor in many tissues, such as vascular smooth muscle and the adrenal gland. Azilsartan Kamedoxomil, a prodrug form of azilsartan 2, was approved in 2011, and is used for the treatment of hypertension. It is marketed by Takeda under the brand name of Edarbi ${ }^{\circledR}$. Azilsartan Kamedoxomil 1 is chemically known as (5-methyl-2-oxo-1,3-dioxol-4-yl) methyl 2-ethoxy-1-\{[2'-(5-oxo-4,5-dihydro-1,2,4-oxadiazol3-yl)biphenyl-4-yl]methyl $\}-1 H$-benzimidazole-7-carboxylate potassium salt. Azilsartan $\mathbf{2}$ is chemically known as

\footnotetext{
* Corresponding author

e-mail: srinivasgaraga@yahoo.com
}

2-ethoxy-1-\{[2 -(5-oxo-4,5-dihydro-1,2,4-oxadiazol-3-yl) biphenyl-4-yl]methyl $\}$-1 $H$-benzimidazole-7-carboxylic acid.
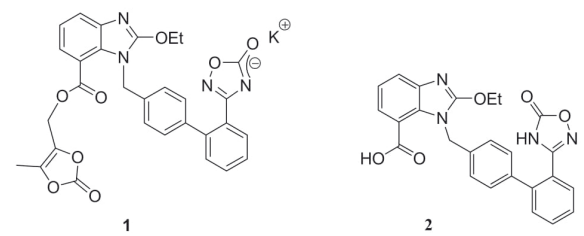

Figure 1. Structures of Azilsartan Kamedoxomil 1 and Azilsartan 2

The presence of impurities in an Active Pharmaceutical Ingredient (API) will influence the quality and safety of the drug product. In the regulatory guidelines of the International Conference on Harmonization (ICH), it is recommended that impurities amounting to more than $0.1 \%$ [5] should be identified and characterized. Impurities are required to be in pure form to check the analytical performance characteristics such as specificity, linearity, range, accuracy, precision, limit of detection (LOD), limit of quantification, robustness, system suitability testing and relative retention factor [4]. 
During the process development of Azilsartan Kamedoxomil 1 in our laboratory, we observed the formation of four substances that are related to Azilsartan Kamedoxomil. These unknown related substances were identified, as well as monitored, and their structures were tentatively assigned on the basis of their fragmentation patterns in LC-MS. In the present work, the identified related substances of Azilsartan Kamedoxomil 1 were synthesized and then characterized by various spectroscopic techniques. Moreover, they were further confirmed by co-injection studies using qualitative HPLC analysis.

\section{EXPERIMENTAL}

Solvents and reagents were obtained from commercial source and used without purification. The IR spectra $\left(\vartheta \max , \mathrm{cm}^{-1}\right)$ were recorded in solid state $\mathrm{KBr}$ dispersion, using a Perkin Elmer FT-IR spectrometer. The ${ }^{1} \mathrm{H}-\mathrm{NMR}$ and ${ }^{13} \mathrm{C}$-NMR spectra were recorded on a Bruker-Avance $300 \mathrm{MHz}, 500 \mathrm{MHz}$ and a $125 \mathrm{MHz}$ spectrometer. The chemical shifts were reported in $\delta / \mathrm{ppm}$ relative to TMS. The mass spectra were then recorded on a API 2000 Perkin Elmer PE-Sciex mass spectrometer. The reactions were monitored by High pressure liquid chromatography (HPLC). Melting points were determined via a polman melting point apparatus (Model No MP96) by the open capillary method, and are uncorrected.

\section{2-Ethoxy-3-[[4-[2-[4-[(5-methyl-2-oxo-1,3-dioxol-4-yl) methyl]-5-oxo-1,2,4-oxadiazol-3-yl]phenyl]phenyl] methyl]benzimidazole-4-carboxylic acid (azilsartan N-medoxomil, 9)}

To a solution of Azilsartan (10 g, $21.92 \mathrm{mmol})$ in DMF (30 mL), we added medoxomil chloride (2.6 g, $17.53 \mathrm{mmol})$ at $25-30^{\circ} \mathrm{C}$. The reaction mass was stirred for $1 \mathrm{~h}$ and the reaction mass was poured into $\mathrm{DM}$ water $(300 \mathrm{~mL})$. We then stirred the reaction mass for $1 \mathrm{~h}$, filtered the product and dried the white colored compound results 9 (7 g, 57\%). The analytical results are as followed: HPLC Purity: 98.36\%; IR (KBr pellet): 3662, 2990, 1778, 1730, 1614, 1552, 1287, $1221,1132 \mathrm{Cm}^{-1}$; ${ }^{1} \mathrm{H}$ NMR $\left(500 \mathrm{MHz}\right.$, DMSO- $\left.d_{6}\right) \delta$ : 7.76037.722 (m, 5H, Ar), 7.49-7.519 (m, 1H, Ar), 7.172-7.255 (m, $3 \mathrm{H}, \mathrm{Ar}), 7.007-7.034$ (d, 2H, Ar), 5.635(s, 2H, N- $\left.\underline{\mathrm{CH}}_{2}-\mathrm{Ar}\right)$, 4.574-4.597 (q, 2H, COOCH$)$ ), $4.152\left(\mathrm{~s}, 2 \mathrm{H}, \underline{\mathrm{OCH}}_{2} \underline{\mathrm{CH}}_{3}\right)$, $1.620\left(\mathrm{~s}, 3 \mathrm{H}, \mathrm{CH}_{3}\right), 1.352-1.399\left(\mathrm{t}, 3 \mathrm{H}, \mathrm{OCH}_{2} \mathrm{CH}_{3}\right)$; ${ }^{13} \mathrm{C}$ NMR (125 MHz, DMSO- $\left.d_{6}\right) \delta: 167.50,158.26,158.11$, $157.77,151.23,141.62,140.71,139.07,137.60,136.92$, $132.58,131.20,131.12,131.04,130.51,128.55,128.18$, 126.99, 123.29, 121.37, 120.46, 116.67, 66.48, 46.33, 40.00, 39.83, 39.66, 39.50, 39.16, 38.99, 34.68, 14.31, 8.08; HRMS for $\mathrm{C}_{30} \mathrm{H}_{25} \mathrm{~N}_{4} \mathrm{O}_{8}(\mathrm{M}+\mathrm{H})^{+}$. Calcd: 569.1628; found: 569.1688 .

(5-methyl-2-oxo-1,3-dioxol-4-yl)methyl 2-ethoxy3-[[4-[2-[4-[(5-methyl-2-oxo-1,3-dioxol-4-yl)methyl]5-oxo-1,2,4-oxadiazol-3-yl]phenyl]phenyl]methyl]benzimidazole-4-carboxylate (azilsartan dimedoxomil, 10).

To a solution of azilsartan $(10 \mathrm{~g}, 21.92 \mathrm{mmol})$ in DMF $(25 \mathrm{~mL})$, we added potassium carbonate $(3.78 \mathrm{~g}, 27.4 \mathrm{mmol})$ and potassium iodide $(0.6 \mathrm{~g}, 6 \%)$ at $25-30^{\circ} \mathrm{C}$. We then raised the reaction mass temperature to $40-45^{\circ} \mathrm{C}$ and added medoxomil chloride $(4.1 \mathrm{~g}, 27.4 \mathrm{mmol})$. The reaction mass was first stirred for $2 \mathrm{~h}$ at $40-45^{\circ} \mathrm{C}$, then poured into DM water $(250 \mathrm{~mL})$ at $20-25^{\circ} \mathrm{C}$, and the $\mathrm{pH}$ adjusted to 7.2 with diluted hydrochloric acid. We stirred the product for $1 \mathrm{~h}$, and filtered and dried the results: a white colored compound $\mathbf{1 2}$ $(9.6 \mathrm{~g}, 65 \%)$. The analytical results are as follows: IR ( $\mathrm{KBr}$ pellet): $3635,3413,2983,1780,1717,1616,1551,1279$, $1226,1119 \mathrm{Cm}^{-1}$; ${ }^{1} \mathrm{H}$ NMR $\left(500 \mathrm{MHz}, \mathrm{DMSO}-d_{6}\right) \delta: 7.728-$ 7.744 (m, 3H, Ar), 7.713-7.717 (m, 2H, Ar), 7.516-7.519 (d, 1H, Ar), 7.213-7.240 (m, 3H, Ar), 6.966-6.994 (d, 2H, Ar) $5.527\left(\mathrm{~s}, 2 \mathrm{H}, \mathrm{N}-\underline{\mathrm{CH}}_{2}-\mathrm{Ar}\right), 5.113\left(\mathrm{~s}, 2 \mathrm{H}, \mathrm{CH}_{2}\right) 4.562-4.632$ (q, $\left.2 \mathrm{H}, \mathrm{COOCH} \underline{\mathrm{H}}_{2}\right), 4.154\left(\mathrm{~s}, 2 \mathrm{H}, \mathrm{OCH}_{2} \mathrm{CH}_{3}\right), 2.138(\mathrm{~s}, 3 \mathrm{H}$, $\left.\mathrm{CH}_{3}\right), 1.401\left(\mathrm{~s}, 3 \mathrm{H}, \underline{\mathrm{CH}}_{3}\right), 1.354-1.393$ (t, $\left.3 \mathrm{H}, \mathrm{OCH}_{2} \underline{\mathrm{CH}}_{3}\right)$; HRMS for $\mathrm{C}_{35} \mathrm{H}_{29} \mathrm{~N}_{4} \mathrm{O}_{11}(\mathrm{M}+\mathrm{H})^{+}$. Calcd: 681.1788 ; found: 681.1823.

\section{(5-methyl-2-oxo-1,3-dioxo-4yl)methyl \\ 1-[2'-(4,5-dihydro-5-oxo-4H-1,2,4-oxadiazol-3-yl) biphenyl-4-yl]methyl]-2-methoxy-1H-benzimidazole- 7-carboxylate a (methoxy analogue of azilsartan medoxomil, 11)}

To a solution of methoxy analogue of azilsartan (10 g, $22.62 \mathrm{mmol})$ in dimethylacetamide $(100 \mathrm{~mL})$, we added medoxomil alcohol $(4.11 \mathrm{~g}, 31.67 \mathrm{mmol})$ at $25-30^{\circ} \mathrm{C}$. We then cooled the reaction mass to $-10^{\circ} \mathrm{C}$ to $-15^{\circ} \mathrm{C}$, and added p-toluenesulfonyl chloride (6.15 g, $32.34 \mathrm{mmol})$, DMAP (0.6 g, $4.97 \mathrm{mmol}$ ) and potassium carbonate (4.12 g, 29.8 $\mathrm{mmol})$ at -10 to $-15^{\circ} \mathrm{C}$. Subsequently, we raised the reaction mass temperature to $10-15^{\circ} \mathrm{C}$, stirred the reaction mass for $2 \mathrm{~h}$, then poured the reaction mass into DM water $(500 \mathrm{~mL})$ and adjusted $\mathrm{pH}$ to 4.0 with diluted hydrochloric acid. We then stirred the product for $1 \mathrm{~h}$, filtered and dried the results: a white compound 11 (10.2 g, 80\%). The analytical results are as follows: HPLC Purity: $95.23 \%$; IR (KBr pellet): 3662, 3010, 1785, 1731, 1617, 1297, 1229, $1109 \mathrm{Cm}^{-1}$; ${ }^{1} \mathrm{H}$ NMR (500 MHz, DMSO- $\left.d_{6}\right) \delta: 7.678-7.693$ (m, 2H, Ar), 7.651-7.664 (m, 1H, Ar), 7.548-7.577 (m, 2H, Ar), 7.2117.379 (m, 1H, Ar), 7.179-7.194 (m, 3H, Ar), 7.048-7.065 (d, 2H, Ar), 5.382 (s, 2H, N- $\left.\underline{\mathrm{CH}}_{2}-\mathrm{Ar}\right), 5.061$ (s, 2H, $\underline{\mathrm{CH}}_{2}$ ), $3.473\left(\mathrm{~s}, 3 \mathrm{H}, \mathrm{CH}_{\underline{3}}\right) 2.17\left(\mathrm{~s}, 3 \mathrm{H}_{\underline{\underline{C}} \underline{\mathrm{H}}_{3}}\right)$; HRMS for $\mathrm{C}_{\underline{29}} \mathrm{H}_{\underline{2}} \mathrm{~N}_{4} \mathrm{O}_{\underline{8}}$ $(\mathrm{M}+\mathrm{H})^{+}$. Calcd: 555.1471; found: 555.1776.

\section{Methyl 1-((2'-amidobiphenyl-4-yl)methyl)-2-ethoxy- 1H-benzo[d]imidazole-7-carboxylate (amide methyl ester 12)}

To a solution of BEC methyl ester (10 g, $24.33 \mathrm{mmol}$ ) in dimethyl sulfoxide $(50 \mathrm{~mL})$, we added a $30 \% \mathrm{w} / \mathrm{w}$ hydrogen peroxide $(8.2 \mathrm{~g}, 72.92 \mathrm{mmol})$ solution at room temperature. We then stirred the reaction mixture for 24 $\mathrm{h}$ at $25-30^{\circ}$, and poured the reaction mass in to DM water $(300 \mathrm{~mL})$. The resulting solid was subsequently filtered and purified, giving the titled compound 12 ( $5 \mathrm{~g}, 50 \%)$. This was characterized as follows: HPLC purity: $97.59 \%$; ${ }^{1} \mathrm{H}$ NMR

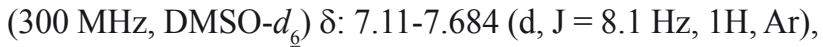
7.618 (s, 1H, Ar), 7.465-7.389 (m, 4H, Ar), 7.339-7.194 (m, 5H, Ar), 6.965-6.938 (d, J = 8.1 Hz, 2H, $-\mathrm{CONH}_{2}$ ), 5.518 (s, 2H, N- $\left.\underline{\mathrm{CH}}_{2}-\mathrm{Ar}\right), 4.587-4.657$ (q, 2H, $\underline{\mathrm{OCH}}_{2} \mathrm{CH}_{3}$ ), $3.707\left(\mathrm{~S}, 3 \mathrm{H}, \mathrm{OCH}_{3}^{2}\right), 1.394-1.441(\mathrm{t}, \mathrm{J}=6.9,4.8 \mathrm{~Hz}, 3 \stackrel{3}{\mathrm{H}}$, $\mathrm{OCH}_{2} \underline{\mathrm{CH}}_{3}$ ); IR (KBr pellet): 2994, 1768, 1717, 1614, 1542, $1281,1135 \mathrm{Cm}^{-1}$. 


\section{RESULTS AND DISCUSSION}

Several routes are available in literature $[2,3,6-11,13$, $15,16,20]$ for the synthesis of Azilsartan Kamedoxomil, the synthetic route [13] for azilsartan kamedoxomil 1 being shown in Scheme 1. The process involves the reaction of methyl 1-((2'-cyanobiphenyl-4-yl)methyl)-2-ethoxy-1Hbenzo[d]imidazole-7-carboxylate (BEC methyl ester, 5) with hydroxylamine hydrochloride in the presence of sodium methoxide, to produce amidoxime $\mathbf{6}$. The treatment of $\mathbf{6}$ with ethyl chloroformate in the presence of a base produces an intermediate $\mathbf{6 a}$, which is cyclized in xylene at reflux to produce azilsartan methyl ester 7. Hydrolysis of 7 in aqueous sodium hydroxide subsequently produces Azilsartan $\mathbf{2}$.

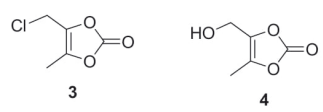

Figure 2. Structures of medoxomil chloride (3) and medoxomil alcohol (4)

Finally, azilsartan (2) treated with medoxomil alcohol (4) in the presence of tosyl chloride produces azilsartan medoxomil (8). Azilsartan medoxomil (8) is then treated with potassium 2-ethylhexanoate in acetone to produce azilsartan kamedoxomil 1, with a $60 \%$ yield.

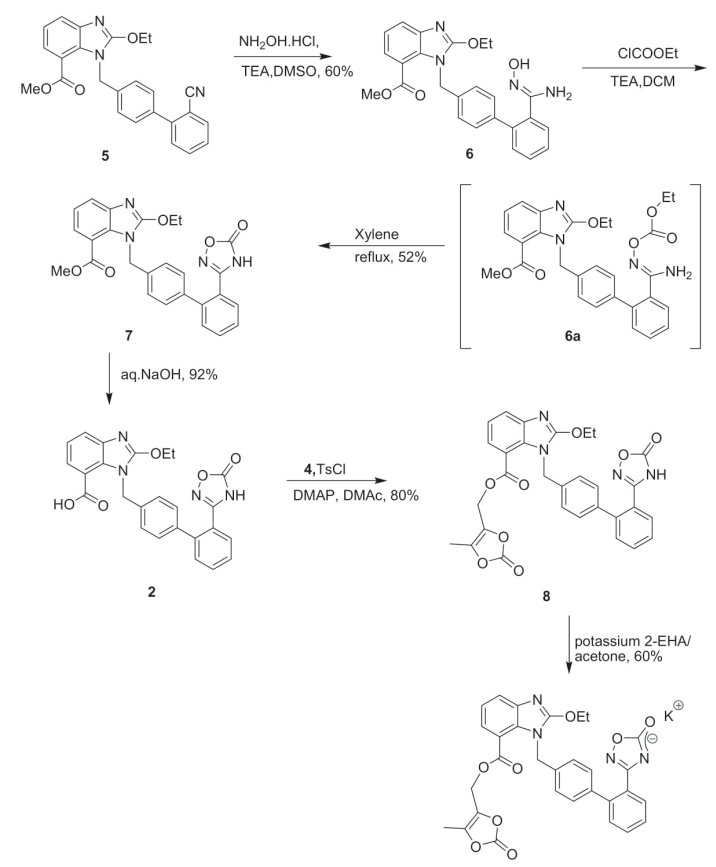

Scheme 1. Synthesis of Azilsartan Kamedoxomil 1

Only a few references $[15,17-20]$ were found in the literature for the related substances of Azilsartan Kamedoxomil 1. During the synthesis of Azilsartan Kamedoxomil in laboratory, we observed the presence of four related substances. The identified were related substances of Azilsartan Kamedoxomil, and their structures and chemical names were confirmed as:

1. 2-Ethoxy-3-[[4-[2-[4-[(5-methyl-2-oxo-1,3-dioxol-4-yl) methyl]-5-oxo-1,2,4-oxadiazol-3-yl]phenyl]phenyl] methyl]benzimidazole-4-carboxylic acid (azilsartan $\mathrm{N}$-medoxomil, 9).
2. (5-methyl-2-oxo-1,3-dioxol-4-yl)methyl 2-ethoxy-3[[4-[2-[4-[(5-methyl-2-oxo-1,3-dioxol-4-yl)methyl]5-oxo-1,2,4-oxadiazol-3-yl]phenyl]phenyl]methyl]benzimidazole-4-carboxylate (azilsartan dimedoxomil, 10).

3. (5-methyl-2-oxo-1,3-dioxo-4yl)methyl 1-[2'-(4,5-dihydro-5-oxo-4H-1,2,4-oxadiazol-3-yl)biphenyl-4-yl] methyl]-2-methoxy-1H-benzimidazole-7-carboxylate (methoxy analogue of azilsartan medoxomil, 11).

4. Methyl 1-((2'-amidobiphenyl-4-yl)methyl)-2-ethoxy-1Hbenzo[d]imidazole-7-carboxylate (amide methyl ester, 12).

The origin, synthesis and characterization of these related substances are described individually below. The synthetically prepared related substances were characterized by conventional spectroscopic studies, and the presence of these related substances in the Azilsartan Kamedoxmil batch was confirmed by spiking the related substances individually with Azilsartan Kamedoxmil. These studies confirmed the formation of related substances (9-12) during the standard manufacturing process of Azilsartan Kamedoxomil 1.

\section{Origin and synthesis of compound 9 (Azilsartan N-medoxomil)}

Compound $\mathbf{9}$ is formed due to condensation of medoxomil chloride $\mathbf{3}$ at the isoxazole ring in azilsartan $\mathbf{2}$.
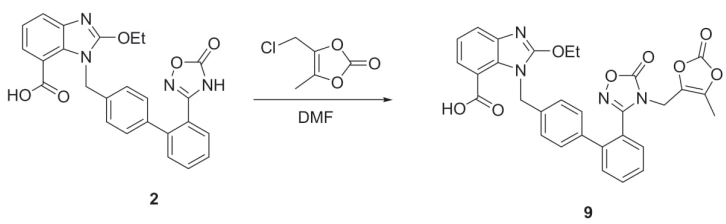

Scheme 2. Synthesis of Azilsartan N-medoxomil 9

Compound 9 was confirmed by IR, Mass, NMR spectral data and co-injection with an authentic sample. The mass spectrum of compound 9 showed a molecular ion at $\mathrm{m} / \mathrm{z}$ 569.1688. The NMR spectrum showed a singlet at $\delta 4.15$, corresponding to $-\mathrm{N}^{-\mathrm{CH}_{2}}$, and a broad singlet at $\delta 13$, corresponding to $-\mathrm{COOH}$. Furthermore, the infrared (IR) spectrum showed absorptions at 1614, corresponding to $\mathrm{C}=\mathrm{O}$ stretching - also confirming the assigned structure.

\section{Origin and synthesis of compound 10 (Azilsartan dimexomil)}

Compound $\mathbf{1 0}$ is formed due to the condensation of medoxomil chloride $\mathbf{3}$ at the isoxazole ring in azilsartan medoxomil 8.
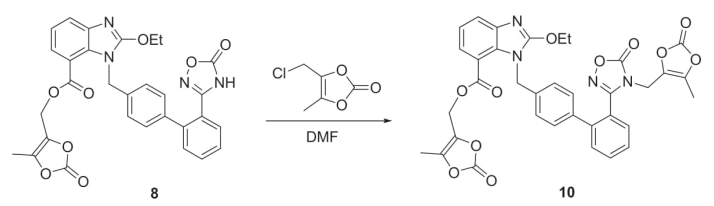

Scheme 3. Synthesis of Azilsartan dimedoxomil 10

Compound 10 was confirmed by IR, Mass, NMR spectral data and co-injection with an authentic sample. The mass spectrum of compound $\mathbf{1 0}$ showed a molecular ion at $\mathrm{m} / \mathrm{z}$ 681.1823. In addition, the NMR spectrum showed a singlet at $\delta 4.15,5.11,1.61 \& 2.15$ corresponding to $-\mathrm{N}-\mathrm{CH}_{2}$, 
$-\mathrm{O}-\mathrm{CH}_{2}$ and two $-\mathrm{CH}_{3}$ of the medoxomil group, while the Infrared (IR) spectrum showed absorptions at 1616, corresponding to $-\mathrm{C}=\mathrm{O}$ stretching - also confirming the assigned structure $\mathbf{1 0 .}$

\section{Origin and synthesis of compound 11 (Methoxy analogue of Azilsartan medoxomil)}

Compound $\mathbf{1 1}$ originates from BEC methyl ester raw material. The methoxy analogue of BEC methyl ester is present as an impurity in BEC methyl ester raw material, and may undergo all the reactions employed in the synthesis of Azilsartan medoxomil, to give compound $\mathbf{1 1}$.

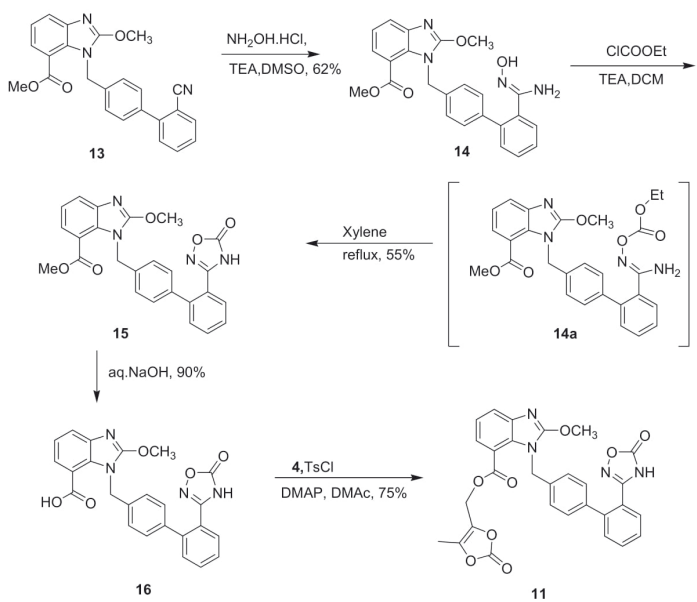

Scheme 4. Synthesis of Methoxy analogue of Azilsartan medoxomil 11

Compound 11 was confirmed by IR, Mass, NMR spectral data and co-injection with an authentic sample. The mass spectrum of compound $\mathbf{1 1}$ showed a molecular ion at $\mathrm{m} / \mathrm{z}$ 555.1776. What is more, the NMR spectrum showed a singlet at $\delta 12.42$, corresponding to $-\mathrm{NH}$, and the absence of $-\mathrm{OCH}_{2}$ protons - also confirming the assigned structure. Moreover, the Infrared (IR) spectrum showed absorptions at 1617 , corresponding to $-\mathrm{C}=\mathrm{O}$ stretching - also confirming the assigned structure.

\section{Origin and synthesis of compound 12 (Amide methyl ester)}

Compound $\mathbf{1 2}$ is a major impurity in amidoxime methyl ester 6 preparation. It comes about because most of the reported methods for preparing amidoxime methyl ester 6 use an excess of hydroxylamine hydrochloride (18 to 25 mole equivalents). Hydroxylamine tends to decompose at higher temperature by giving ammonia as a by-product. This ammonia then reacts with BEC methyl ester $\mathbf{5}$, to give amide methyl ester $\mathbf{1 2}$ as a related substance. In our work, the amide methyl ester was independently prepared by treating BEC methyl ester $\mathbf{5}$ with hydrogen peroxide in dimethyl sulfoxide.

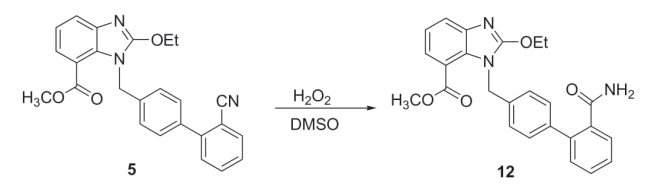

Scheme 5: Synthesis of Amide methyl ester 12
Compound 12 was confirmed by IR, Mass, NMR spectral data (experimental section 3.6) and co-injection with an authentic sample. The mass spectrum of compound $\mathbf{1 2}$ showed a molecular ion at $\mathrm{m} / \mathrm{z} 430.1769$. In comparison with BEC methyl ester 5, the NMR spectrum showed a singlet at $\delta 6.938$ corresponding to $-\mathrm{CONH}_{2}$, while the Infrared (IR) spectrum showed absorptions at 3518 and 1622, corresponding to $-\mathrm{NH}_{2}$ and $-\mathrm{C}=\mathrm{O}$ stretching - also confirming the assigned structure.

\section{CONCLUSION}

The process related substances in Azilsartan Kamedoxomil were identified, synthesized and characterized by using ${ }^{1} \mathrm{H}$ NMR, ${ }^{13} \mathrm{C}$ NMR, MS and IR techniques. Further, these related substances were co-injected with Azilsartan Kamedoxomil to confirm the retention time in HPLC. This related substances study of Azilsartan Kamedoxomil is, is hence, useful to the pharmaceutical industry.

\section{ABBREVATIONS}

TsCl, Para-toluenesulfonyl chloride;

DMSO, dimethyl sulfoxide;

DMAP, dimethylaminopyridine;

DMAc, N,N-dimethylacetamide;

DMF, N,N-dimethylformamide;

$\mathrm{TrCl}$, Trityl chloride;

DSC, disuccinimidyl carbonate;

TFA, trifluoroacetic acid;

DIBOC, Di tert-butyl dicarbonate;

DMC, dimethyl carbonate;

DEC, diethyl carbonate;

DPC, diphenyl carbonate;

CDI, carbonyldiimidazole;

ECF, ethyl chloroformate;

HPLC. High pressure liquid chromatography;

LCMS, Liquid chromatography-mass spectrometry.

\section{ACKNOWLEDGMENTS}

The authors gratefully acknowledge the management of Aurobindo Pharma Limited for allowing us to carry out this research work.

\section{REFERENCES}

1. Aulakh G.K., Sodhi R.K., Singh M.: An update on non-peptide angiotensin receptor antagonists and related RAAS modulators. J. Life Sci., 81, 615, 2007.

2. Bansal D. et al.: An improved process for the preparation of azilsartan medoxomil. Patent WO/2012/107814, 2012.

3. Dubey S. K. et al.: Indian patent Appl.No.IN2011DE01901 A 20131004.

4. International Conference on Harmonization (ICH) guidelines. Q2B validation of analytical procedure: Methodology. ICH guidelines: Geneva, Switzerland, November, 1996.

5. International Conference on Harmonization (ICH) guidelines. Q3A (R) impurities in New Drug Substances. ICH guidelines: Geneva, Switzerland, February, 2002.

6. Jo N. et al.: A manufacturing method for azilsartan. Patent WO/2012/157980, 2012.

7. Kohara Y. et al.: A new class of angiotensin II receptor antagonists with a novel acidic bioisostere. Bioorg. Med. Chem. Lett., 5, 1903, 1995. 
8. Kohara Y. et al.: Synthesis and Angiotensin II Receptor Antagonistic Activities of Benzimidazole Derivatives Bearing Acidic Heterocycles as Novel Tetrazole Bioisosteres. J. Med. Chem., 39, 5228, 1996.

9. Kshirsagar P. B. et al.: The process for the preparation of azilsartan medoxomil. Patent WO/2013/042066, 2013.

10. Kubo K. et al.: Nonpeptide angiotensin II receptor antagonists. Synthesis and biological activity of benzimidazolecarboxylic acids. J. Med. Chem., 36, 2182, 1993.

11. Kuroita T. et al.: Compound which is an angiotensin antagonist. U.S. Patent No.7, 157, 584.

12. Miura S., Karnik S.S., Saku K.: Ability of the new AT1 receotir blocker azilsartan to block angiotensin II-induced AT1 receptor activation after wash-out. J. Renin Angiotensin Aldosterone Syst., 12, 1, 2011.

13. Naka T. K., Inada. Y.: (Takeda Chem. Ind). U.S.Patent No.5, 243, 054

14. Radl S. et al.: Synthesis of Azilsartan and its selected potential impurities. J. Heterocyclic Chem., 50, 929, 2013
15. Radl S., Stach J.: A method of preparing 2-ethoxy-1-((2'-(5-oxo-4,5dihydro-1,2,4-oxadiazol-3-yl)biphenyl-4-yl)methyl)-1H-benzo[d] imidazole-7-carboxylates and conversion thereof to azilsartan. WO/2012/139535. 2012.

16. Raghavareddy A. V. et al.: A novel process for the preparation of Azilsartan medoxomil. Indian patent App. No. 4226/CHE/2012A.

17. Sangeeta S. et al.: Synthesis and Characterization of Impurities of a Common and Advanced Intermediate of Candesartan and Azilsartan Antihypertensive Drugs. Int. Res. J. Pure App. Chem., $5,140,2015$

18. Sethi M. K. et al.: Related substances of azilsartan medoxomil: synthesis and characterization. Der Pharma Chemica, 7, 20, 2015.

19. Srinivas G. et al.: Commercial synthesis of Azilsartan Kamedoxomil: An angiotensin II receptor blocker. Org. Process Res. Dev., 19, 514, 2015.

20. Stanislav R. et al.: Improved process for Azilsartan medoxomil: A new angiotensin receptor blocker. Org. Process Res. Dev., 17, 77, 2013. 